\title{
Research Article \\ Self-Monitoring Strengthening System Based on Carbon Fiber Laminate
}

\author{
Rafal Krzywon, ${ }^{1}$ Marcin Gorski, ${ }^{1}$ Szymon Dawczynski, ${ }^{1}$ Leszek Szojda, ${ }^{1}$ \\ Joao Castro Gomes, ${ }^{2}$ and Rita Salvado ${ }^{3}$ \\ ${ }^{1}$ Faculty of Civil Engineering, Silesian University of Technology, Gliwice, Poland \\ ${ }^{2} C-M A D E$, Centre of Materials and Building Technologies, University of Beira Interior, Covilhã, Portugal \\ ${ }^{3}$ Research Unit of Fiber Materials and Environmental Technologies (FibEnTech), Universidade da Beira Interior, \\ 6201-001 Covilhã, Portugal
}

Correspondence should be addressed to Marcin Gorski; marcin.gorski@polsl.pl

Received 12 February 2016; Revised 27 April 2016; Accepted 12 May 2016

Academic Editor: Hong-Hu Zhu

Copyright (C) 2016 Rafal Krzywon et al. This is an open access article distributed under the Creative Commons Attribution License, which permits unrestricted use, distribution, and reproduction in any medium, provided the original work is properly cited.

\begin{abstract}
Externally bonded composites reinforced with high-strength fibers are increasingly popular in construction, especially in structures' strengthening, where the best possible mechanical properties are required. At the same time the ability to autodetect threats is one of the most desirable features of contemporary structures. The authors of the paper have developed an intelligent fabric, wherein the carbon fibers play the role of not only tensile reinforcement but also strain sensor. The idea is based on the construction of the strain gauge, where the thread of carbon fibers arranged in zig-zag pattern works as electrical conductor and is insulated by parallel thread of glass or acrylic fibers. Preliminary laboratory tests were designed to create effective measurement techniques and assess the effectiveness of the strengthening of selected building structures, as reinforced concrete and timber beams. Presented in the paper, selected results of these studies are very promising, although there were some noted problems to be considered in next steps. The main problem here is the control of the cross section of the fibers tow, affecting the total resistance of the fabric. One of the main deficiencies of the proposed solution is also sensitivity to moisture.
\end{abstract}

\section{Introduction}

Traditional methods of strengthening of building structures usually mean unpleasant consequences and limitations. The most commonly used cross section enlargement of loadbearing components results in reduction of storage space and additionally, because of the time-consuming building process, indicates the need for long-term exclusion of object from the normal use. What is worse, heavy strengthening becomes a secondary burden for structure. Described drawbacks lead to search for new methods of strengthening, lighter and allowing a better fit to the existing threats. Nowadays the most popular are EBR FRP systems (Externally Bonded Fiber Reinforced Polymer) based on the high-strength organic (carbon, glass, and aramid) or inorganic fibers (basalt and high-strength steel). With the introduction of the fiber reinforcement, the construction can apply other technologies previously reserved for the textile and related industries.
Examples include sensors for monitoring strain, temperature, or humidity borrowed from the technology of intelligent clothing in sports or medicine [1].

Most of the systems for Structural Health Monitoring are based on external sensors such as strain gauges and extensometers and a few recent smart solutions use optical fibers [2], very rarely, yet high-strength fibers themselves [3]. Most interesting solutions refer, however, to cables of bridges [4]. This is why, since 2010, the group of researchers from Silesian University of Technology (Poland) and Universidade da Beira Interior (Portugal) together with industrial partners, FIDIA (Italy), FISIPE (Portugal), and Europrojekt (Poland), decided to undertake efforts in order to create the strengthening solution, which would be able to monitor itself using the electrical features of fibers.

The paper presents the overview of initial tests on structural elements strengthened with carbon fiber smart textile. It shows also idea of currently ongoing first in situ application. 


\section{The Concept and First Laboratory Trials}

The idea of measuring strains by recording changes in the resistance is not new. This phenomenon is the base of work of popular strain gauges invented by Edward E. Simmons and Arthur C. Ruge in 1938 [5]. Also, the concept of selfmonitoring reinforcement is not new and in the 1960s such attempts were performed in Poland, but they had no published reference and no practical implementation due to the very low sensitivity to this measurement technique.

The concept itself was not given up, but it took the form of monitoring of reinforcement with attached strain gauges (ERSG, Electronic Resistance Strain Gauge). This technique is widespread in substantial structures needing constant monitoring. Traditional strain gauges are, however, short and give limited information about the situation in one of the points at the structure. This is why this technique evolves in larger solutions, as LGS (Long-Gauge Strain) [6].

The second stream of research on the measurement of strains focused on conductive materials other than metals. Among new solutions the fibrous materials seemed to be the most attractive. Optical fibers (FOS, Fiber Optic Sensor) for monitoring of concrete structures [7] were implemented already in the late 1990s. Majority of various FOS systems are applied externally on the surface of the structure, but there were elaborated solutions to control strains in reinforcement (Bragg Grating Sensors) [8].

In 1982 Swiss Institute EMPA began works on use of fibrous materials for construction. New material that attracted attention of researchers was based on carbon fibers. First observations of Meier were published in 1987 [9] and first in situ strengthening was conducted in 1991 [10]. Carbon fibers thanks to excellent mechanical (high tensile strength and high modulus of elasticity) and physical (low weight to strength ratio) properties appeared to be most attractive material for strengthening of structures. Today CFRP (Carbon Fiber Reinforced Polymer) is the most popular material for structural upgrades.

Mechanical properties were not the only parameters that attracted attention of researchers. It is commonly known that carbon fibers are conductive material, so there were attempts of employing also this feature in structures. First works on monitoring of structures with the use of carbon fiber were undertaken in the early 1990s by Chen and Chung [11] and then Wang et al. [12], who proved the ability of those fibers for self-diagnosing thanks to registration of the changes of electric resistance in extended fibers. The tests were initially conducted on RC and short carbon fibers composites (CFRC) but they evolved and there were first attempts noted of CFRP use for self-monitoring of structures [13]. Still main idea of the use of fiber sensing was thought for new structures not strengthening of existing structures.

This technique, despite its attractiveness and potential, did not find further interest of researchers and industry. Facing the facts, proving that CFRP became most popular method of structural strengthening, and proving potential of unexplored electrical properties of carbon fibers the team of Silesian University of Technology decided to focus on elaboration of self-monitoring CFRP system of strengthening.

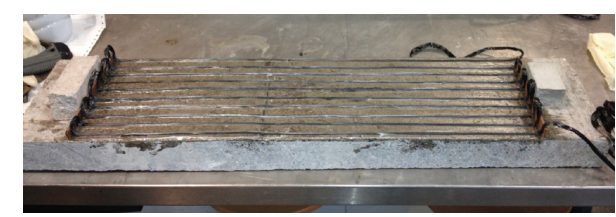

FIGURE 1: Concrete slab with glued CFRP filament of zig-zag pattern.

A typical strain gauge arranges a long, thin conductive wire in a zig-zag pattern of parallel lines such that a small deformation in the direction of the orientation of the parallel wires results in a multiplicatively larger change in resistance and consequently strain measurement. Exactly the same idea was implemented in the construction of the developed smart textile. The electrical conductor plays the role of the carbon fiber tow, exactly the same, which reinforces laminate used for strengthening of structures. Deformation leads to change in electrical resistance allowing self-monitoring of the fabric. The first tests have already shown that changes in resistance for a single tow are too small compared to the technical abilities of recording equipment used (Wheatstone bridge). Increasing the length of the tow by its wiggly lead (copy of zig-zag pattern of strain gauge) significantly improved the sensitivity of the system.

Laboratory tests of prototype made in this way were performed on small models of concrete slabs with adhered carbon fiber thread along the tensile zone (Figure 1). In order to verify indications of smart textile and defining gauge factor parallel, a set of 7 paper strain gauges was adhered. A more detailed description of these studies is presented in [14]. Initially trials confirmed capabilities of developed smart textile in terms of both strengthening and monitoring aspects.

The application of single thread laid in zig-zag pattern in practice would be very difficult and time consuming. To minimize that inconvenience a technique of weaving was developed, where carbon threads were separated by threads of nonconductive acrylic or glass fibers and additionally all woven into the warp cotton. The outlook of prototype of fabric manufactured in this way before and after the lamination is shown in Figure 2.

Gauge based solution proved to be still insufficient for measuring small changes in strain. A further modification was the use of two parallel bundles of carbon fibers placed end to end. This allowed increase in resistivity by measuring the total volume resistance (growing with elongation of carbon fiber) and contact resistance (at the interface of parallel fiber threads). Described concept is shown in Figure 3. Accuracy of such solution has been initially questioned, but obtained results were very promising.

Finally developed prototype of textile sensor is made of woven threads of carbon fibers having cross-sectional $\approx$ 24000 carbon filaments (a density of $1,81 \mathrm{~g} / \mathrm{cm}^{3}$ ) separated by threads of acrylic fiber (density: $1,17 \mathrm{~g} / \mathrm{cm}^{3}$ ) and cotton threads in the warp (density: $1,54 \mathrm{~g} / \mathrm{cm}^{3}$ ). Conductive carbon fibers are unidirectionally laid. The fabric during application is laminated with epoxy resin. Key properties of the fibers 
TABLE 1: Properties of applied carbon fibers and filament.

\begin{tabular}{|c|c|c|c|c|c|c|c|}
\hline $\begin{array}{l}\text { Number of } \\
\text { filaments/thread }\end{array}$ & $\begin{array}{c}\text { Fineness of thread } \\
(\text { tex }=0,001 \mathrm{~g} / \mathrm{m})\end{array}$ & $\begin{array}{c}\text { Tensile } \\
\text { strength (MPa) }\end{array}$ & $\begin{array}{c}\text { Tensile } \\
\text { modulus (GPa) }\end{array}$ & $\begin{array}{c}\text { Elongation at } \\
\text { break (\%) }\end{array}$ & $\begin{array}{c}\text { Filament } \\
\text { diameter } \\
(\mu \mathrm{m})\end{array}$ & $\begin{array}{l}\text { Density } \\
\left(\mathrm{g} / \mathrm{m}^{3}\right)\end{array}$ & $\begin{array}{l}\text { Single filament } \\
\text { resistivity } \\
(\mu \Omega \mathrm{m})\end{array}$ \\
\hline 24000 & 1600 & 5000 & 270 & 1.9 & 7 & 1.81 & 14 \\
\hline
\end{tabular}

TABle 2: Properties of smart textile specimens.

\begin{tabular}{|c|c|c|c|c|c|c|}
\hline Test specimen & Type & $\begin{array}{c}\text { Laminate } \\
\text { thickness }(\mathrm{cm})\end{array}$ & $\begin{array}{c}\text { Carbon fiber } \\
\text { volume fraction }\end{array}$ & $\begin{array}{c}\text { Total fiber } \\
\text { volume fraction }\end{array}$ & $\begin{array}{l}\text { Initial resistance } \\
(\Omega / \mathrm{m})\end{array}$ & $\begin{array}{c}\text { Total } \\
\text { resistance }(\Omega)\end{array}$ \\
\hline $\mathrm{RC}$ beam & & & & & & 164.5 \\
\hline RC beam SRP strengthened & $\begin{array}{c}24 \mathrm{k} / 24 \mathrm{k} \\
\text { carbon fibers }\end{array}$ & $0.17 \pm 0.036$ & 0.12 & 1.9 & 7 & 171.2 \\
\hline Timber beam & & & & & & 174.8 \\
\hline
\end{tabular}

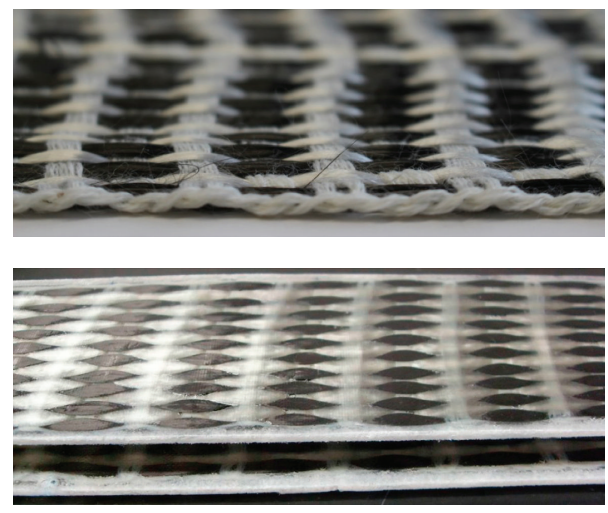

FIGURE 2: Smart textile before and after the lamination.

are shown in Table 1, and the laminate formed in this way is shown in Table 2.

\section{Test Outline}

The next step in verifying the behavior of the developed selfmonitoring and strengthening system was tests of real scale beams. Main part of laboratory tests was conducted on three beams:

(i) reinforced concrete beam with textile sensor (T1) bonded to the bottom side (Figure 4),

(ii) reinforced concrete beam additionally strengthened by two layers of SRP $3 \times 2-12$ tape with textile sensor bonded to the bottom side (Figure 5),

(iii) timber beam with textile sensor bonded to the bottom side (Figure 6).

Laboratory trials were performed in four-point bending test (scheme is shown in Figures 4-6). The textile sensor had a length of $1000 \mathrm{~mm}$ and was adhered along a section of constant bending moment ( $800 \mathrm{~mm}$ long), leaving around $100 \mathrm{~mm}$ as anchorage of both ends. This concept has allowed the registration of almost constant strains along the zone with theoretically invariable curvature.

The textile sensor used in these tests was made of two continuous fiber threads placed end to end, each of $18 \mathrm{~m}$ length. Specific parameters of the sensor used in the following tests are presented in Table 2.

All three beams were loaded monotonically until failure. Force was applied using a hydraulic press; during the test the following were measured:

(i) load value,

(ii) deformation in five points along the beam length (support, force application points, a middle of the span) using inductive sensors (U1-U5),

(iii) resistance of textile sensor (T1),

(iv) strains at 9 points on the length of the tensor fabric using the classic paper-based strain gauges $75 \mathrm{~mm}$ long (G1-G9). Their indication was used to calibrate the gauge factor of the smart textile (T1).

Additionally, to confirm the strengthening abilities of developed sensor, three reference beams were tested without textile sensor applied. Geometry and reinforcement of beams were identical; one of them was not strengthened and the second was strengthened with two layers of CFRP S\&P C Sheet 240 of the same size as textile sensor (length: $1000 \mathrm{~mm}$, width: $150 \mathrm{~mm}$ ). The last was strengthened with two layers of SRP 3×2-12 tape. Sheets, as previously smart textile, were laminated with the use of S\&P Resin 55. SRP tapes were bonded with Sika Sikadur 330 adhesive.

\section{Comparative Measures of Resistance Changes}

Because of an unknown relationship between the elongation and the change in the electrical resistance, strain measurements required calibration. It was made by comparing the averaged indication of reference paper strain gauges. The need for averaging of strain gauges' measures results from the diversity of their indications on the length of smart textile, despite theoretically constant bending moment and constant strain. This is particularly evident in the test of timber beams, where one of the outer gauges measured strain more than twice larger than the middle gauge (Figure 9).

Results of measurements made with a smart textile, with readings adjusted by calibrated gauge factor, with reference to 


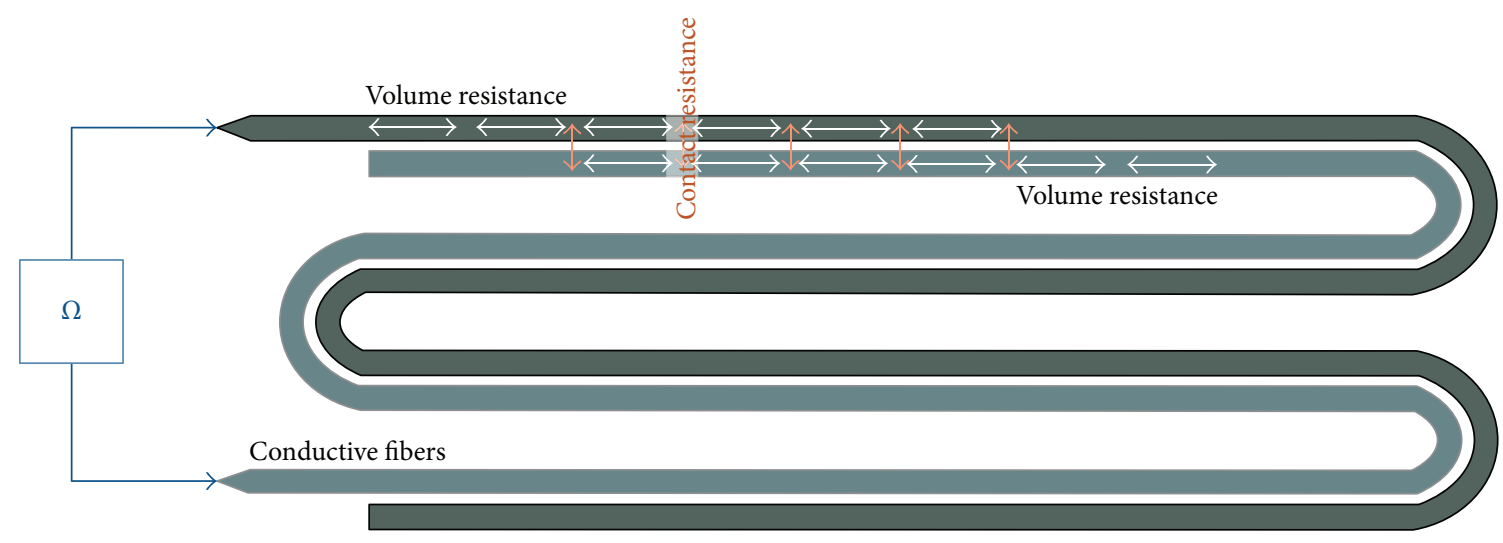

FIGURE 3: Ideogram of smart textile gauge, voltage applied during measures $5 \mathrm{~V}$.

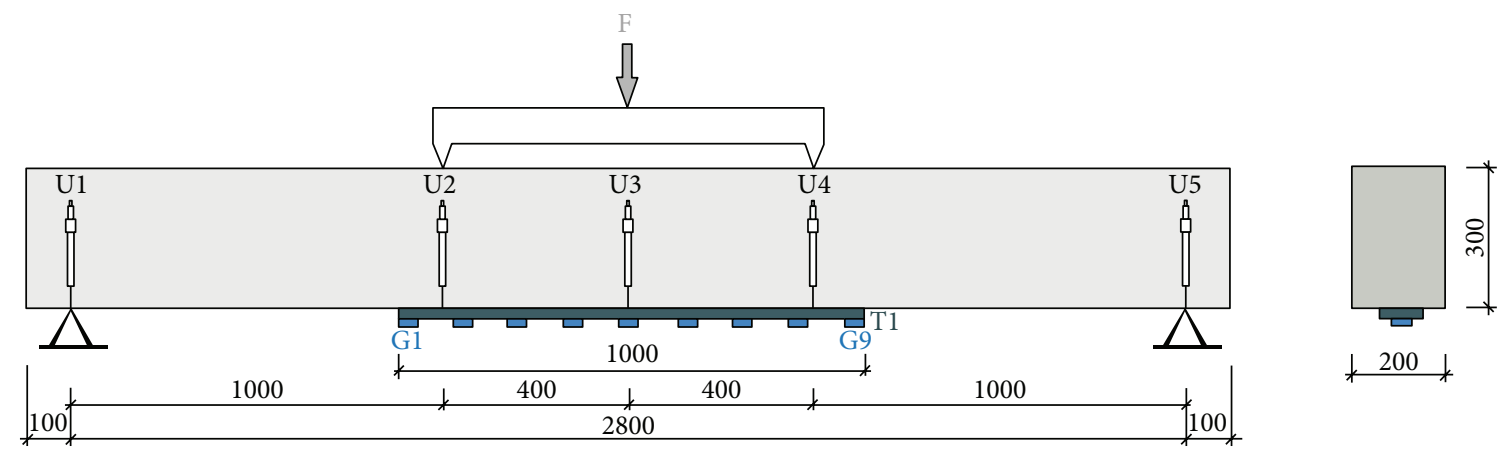

FIGURE 4: Scheme of bending test model on the RC beam strengthened with textile sensor.

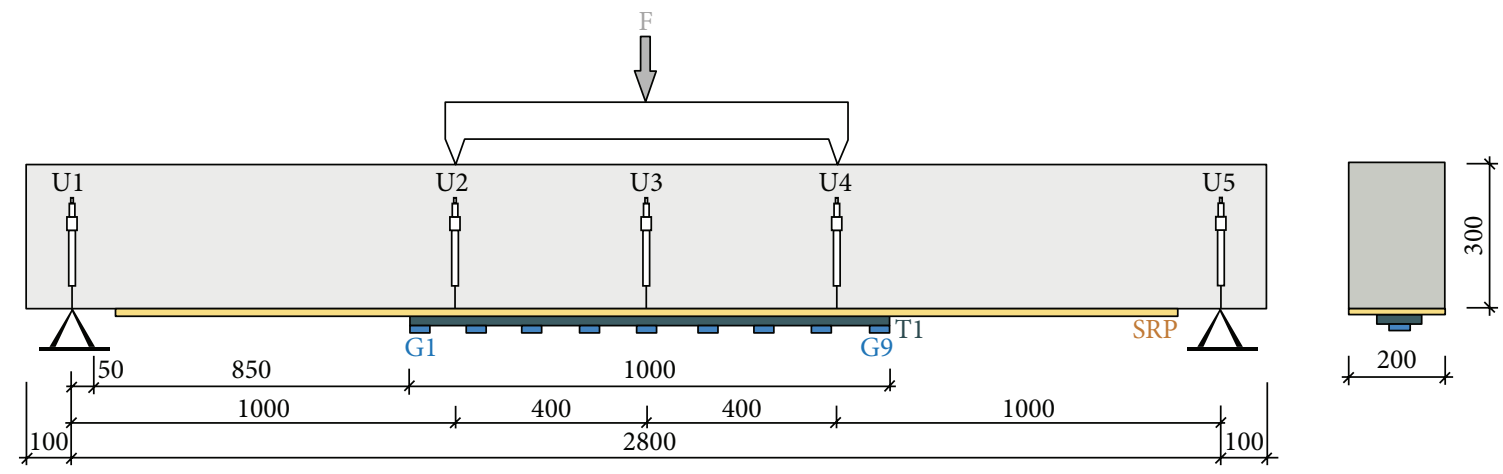

FIGURE 5: Scheme of bending test model on the RC beam strengthened with SRP and textile sensor.

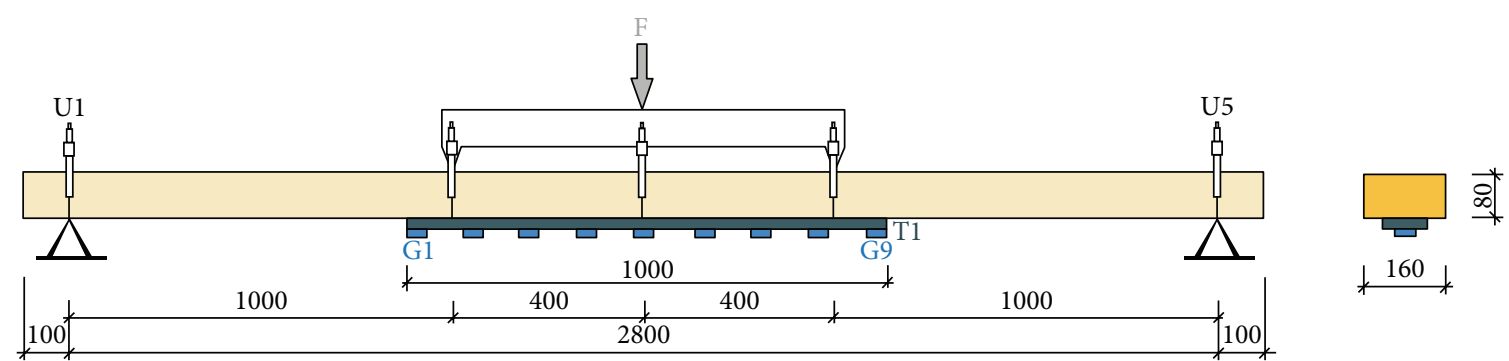

FIGURE 6: Scheme of bending test model on the timber beam strengthened with textile sensor. 


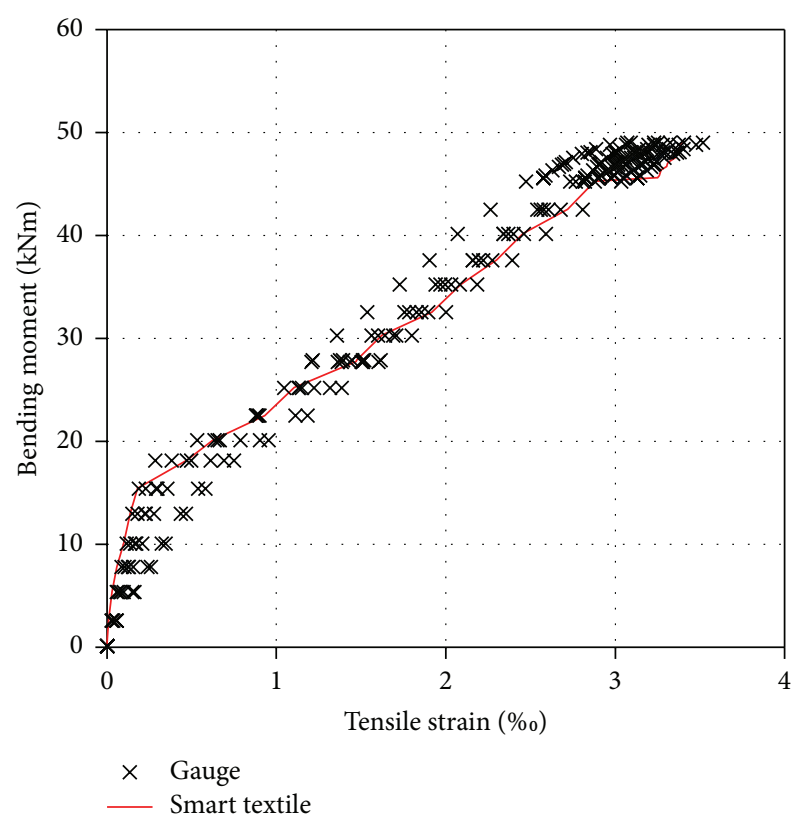

FIGURE 7: Bending moment: tensile strain relationship for RC beam.

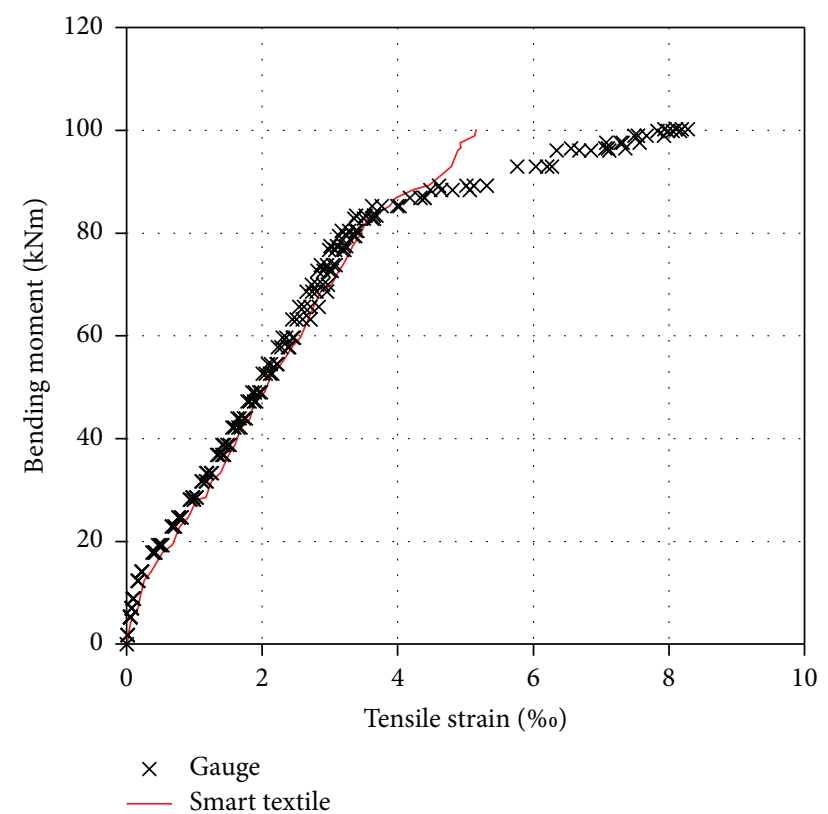

FIGURE 8: Bending moment: tensile strain relationship for RC beam, additionally strengthened with two layers of SRP laminate.

readings from paper strain gauges, are shown on Figures 7, 8, and 9.

Obtained strain resistance dependence of smart textile shows promising compatibility with measures collected from paper strain gauges. The error of indication does not exceed $5 \%$. For reinforced concrete beams the characteristic bent points after the first cracks and reinforcement yield could be clearly seen (Figures 7 and 8). Larger indication error occurs at relatively large deformations exceeding $3 \%$. This can be noticed in the study of timber beam (Figure 9), where

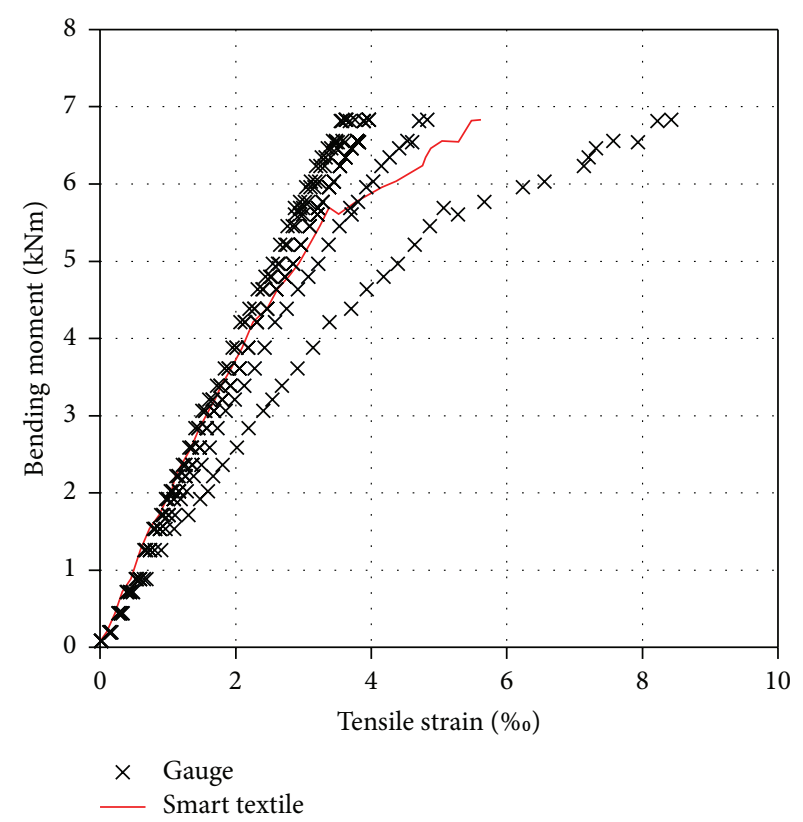

FIGURE 9: Bending moment: tensile strain relationship for timber beam.

bending of the curve appears, and in the study of beams reinforced with SRP tape, where there was a rupture of textile. In the second case, the measurement error is likely to be associated with damage to the fabric, which in the final phase of the study was broken (see Figure 13).

\section{Strengthening Effect}

The first phase of the study took comparative tests of two beams. Beam with attached textile sensor was compared to the beam strengthened with two layers of externally bonded CFRP sheet. Location, the length, and width of both applications were identical. Achieved in this experiment, strengthening effect was much lower than expected and amounted to less than $10 \%$. Similar results were obtained for both compared models (Figure 11). Load-bearing capacity grew by less than $4 \mathrm{kNm}$ in comparison to the reference, not strengthened beam.

The explanation for such poor performance gives the observation of destruction mode of the specimen. The consequence of strengthening application only along the constant bending zone was incorrect anchoring, which should be provided outside the zone of maximum bending. This principle has not been kept, so as a result of a sudden change of rigidity, the edge of strengthening was detached with part of concrete cover (shown in Figure 10).

To avoid this disadvantage textile sensor was combined with conventional externally bonded strengthening made of two layers of hardwire SRP tape $3 \times 2-12$. Primary reinforcement was applied over the entire length of the beam and anchored near the support zones, and textile sensor adhered as an additional layer only along the section of constant bending moment. 


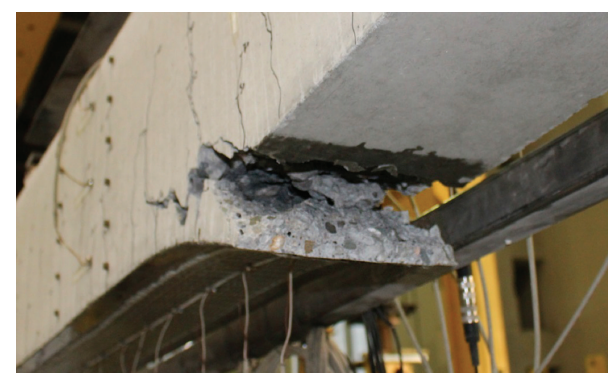

FIGURE 10: Failure of the RC beam as a result of detachment of the sensor in the anchorage zone.

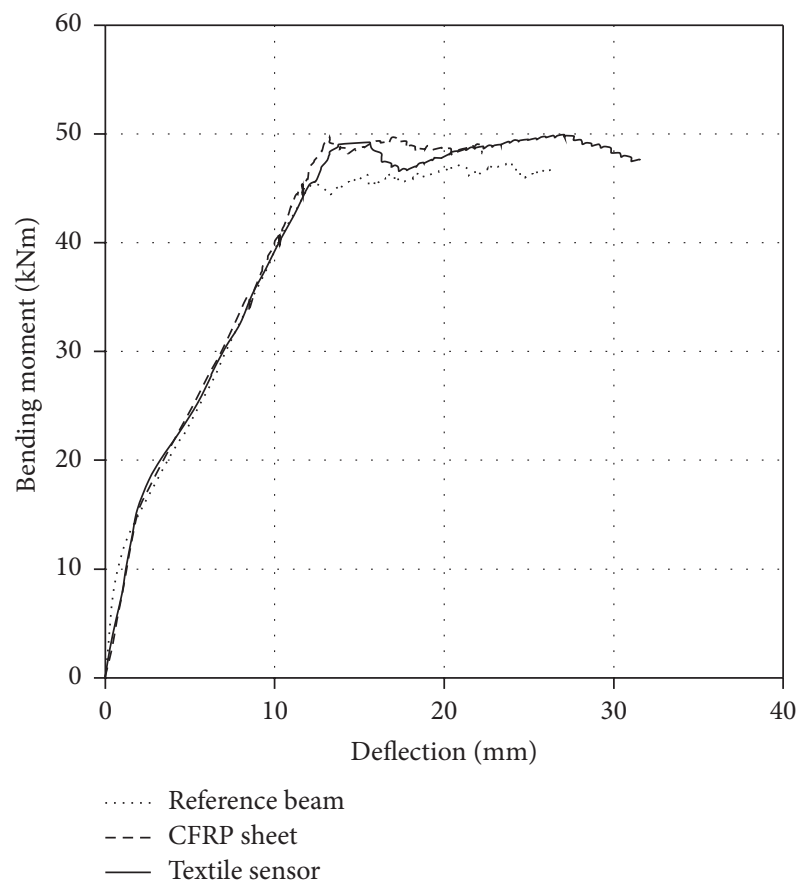

FIGURE 11: Comparison of bending moment: deflection relationships for RC beams.

Terms and methodology of the second experiment were the same as the first concrete beam. Obtained in this test, results are already consistent with those expected. Strengthening effect is clearly visible (Figure 12), and load-bearing capacity grew by more than $9 \mathrm{kNm}$ in comparison to beam without bonded textile sensor. Destruction of the beam was the result of deamination tape SRP, while the sensor has break along and across the grain. Described failure model is shown in Figure 13. This indicates good cooperation of the textile sensor with the rest of the strengthening system.

It should also be highlighted that application of textile sensor allows for the slight reduction of deflection, especially in the phase of the reinforcement yield (Figure 12).

\section{In Situ Applications of Textile Sensor}

Scientific research should aim at the future commercialization of the results. Trial use in the natural conditions may

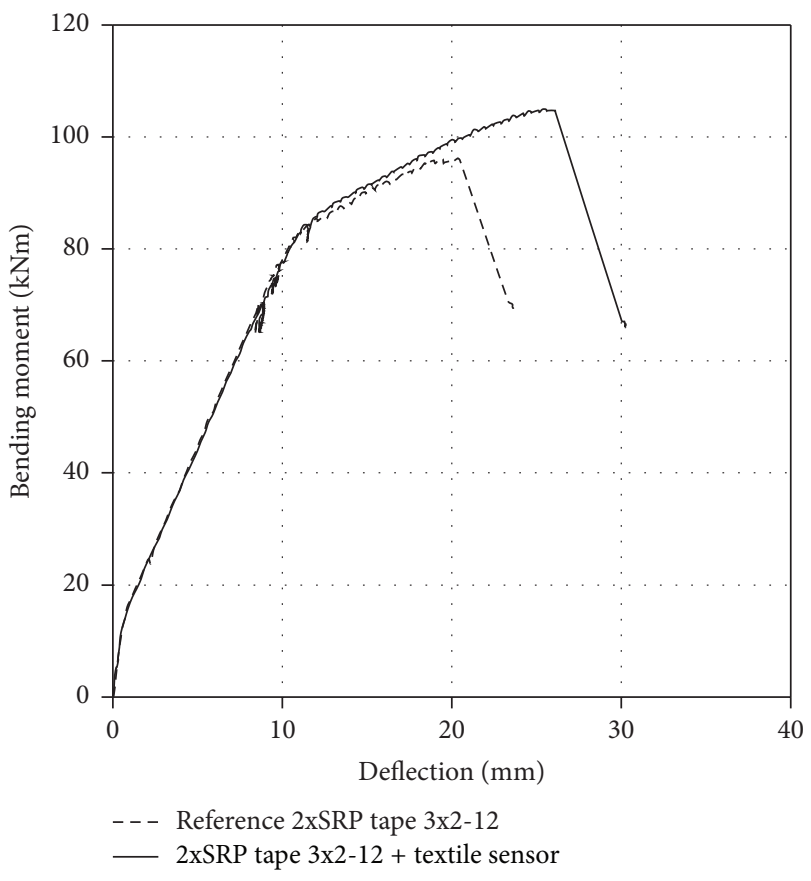

FIGURE 12: Comparison of bending moment: deflection relationships for SRP strengthened beams.

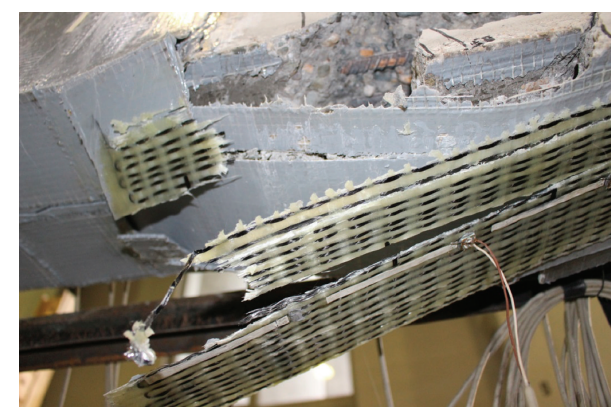

FIGURE 13: Failure of the SRP strengthened beam: visible rupture of textile sensor.

confirm the results of laboratory tests but also can evaluate the sustainability, or even acceptance by future users. Such a study is currently in the first phase of implementation. During renovations of hydroelectric plant in southern Poland, damaged during the floods five years ago, a developed textile sensor (Figure 14) was mounted along one of the beams supporting the engine room. The choice of a side surface was done due to the expected possible deformations and availability for future inspection. The sensor in this location should allow registration of strains caused by bending of the beam.

The textile sensor is sensitive to temperature and moisture changes, so the readings are being calibrated in different environmental conditions to provide correctly filtered alert.

Currently textile sensor is being complemented by the recording equipment with possibility of sending data with the use of GSM. It is expected to start monitoring with 


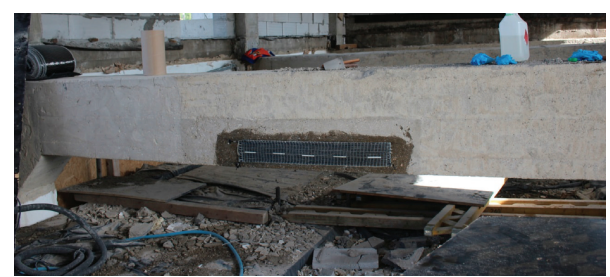

FIGURE 14: In situ application of the textile sensor.

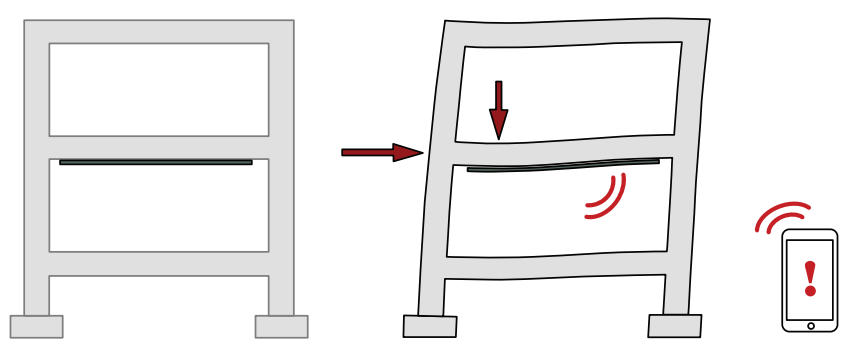

FIGURE 15: Concept of remote monitoring with use of textile sensor.

the progress of repair work, especially the construction of the structure of slab and after restoring the building.

Additionally, there were undertaken works on filtering of the signal allowing to alert the parties interested in the situation of exceeded deformations. The level of the strain corresponding with critical deformation has to be defined initially, considering the geometry of structure, its mechanical properties, and environmental conditions. The alert will vary due to level of the competence of the involved person - the owner will receive only alert with information of critical situation forcing him to undertake means to provide security to people, equipment, and the structure. Inspector or monitoring team shall receive the set of necessary values to define the nature of the hazardous influence and level of the risk for the structure.

General idea of the monitoring with the use of textile sensor is shown in Figure 15.

\section{Additional Points}

The paper describes the testing phases of smart textile sensor for both strengthening and monitoring of building structures. Such properties of carbon fiber were used: high strength and electrical conductivity. Increasing fiber strain leads to change of its conductivity, measured as a change of its electrical resistance. Authors believe that such self-monitoring strengthening system could be particularly attractive to upgrade large structures with difficult access.

First trials were performed on small concrete slabs with glued single filament of fibers; then, due to low sensibility, this solution was modified by the introduction of two parallel threads. Further tests of concrete beams in real size demonstrated the effectiveness of developed prototype in the role of strain gauge and strengthening system. This made it possible to start the first trial in real conditions, which is currently carried out.
In parallel with the mentioned in situ test, the main direction of actual research is to improve the sensitivity of the textile sensor under small (compression of bridge bearing block) and high deformation (bending of timber beams). Initial studies showed some irregularities of large deformation measures, probably related to microcracks of sensors epoxy matrix and excessively increasing contact resistance. Another phenomenon that requires further testing is about a $10 \%$ increase of resistance during lamination.

\section{Competing Interests}

The authors declare that they have no competing interests.

\section{Acknowledgments}

The authors acknowledge C-MADE Center of UBI and Mr. Clemente Pinto for help in realization of preliminary tests and the European Union for financing Project 251373 (FP7-PEOPLE-2009-IAPP)—Intelligent Systems for Structures Strengthening and Monitoring (INSYSM).

\section{References}

[1] L. M. Borges, P. Araújo, A. S. Lebres et al., "Wearable sensors for foetal movement monitoring in low risk pregnancies," Lecture Notes in Electrical Engineering, vol. 75, pp. 115-136, 2010.

[2] K.-T. Lau, "Fibre-optic sensors and smart composites for concrete applications," Magazine of Concrete Research, vol. 55, no. 1, pp. 19-34, 2003.

[3] A. A. Mufti and W. K. Neale, State-of-the-Art of FRP and SHM Applications in Bridge Structures in Canada, Composites \& Polycon, The American Composites Manufacturers Association, Tampa, Fla, USA, 2007.

[4] Z. Zhou, Z. Zhang, N. Deng et al., "Applications of FRP-OFBG sensors on bridge cables," in Smart Structures and Materials: Sensors and Smart Structures Technologies for Civil, Mechanical, and Aerospace Systems, vol. 5765 of Proceedings of SPIE, San Diego, Calif, USA, March 2005.

[5] P. K. Stein, "Strain gage history and the end of the twentieth century," Experimental Techniques, vol. 25, no. 2, pp. 15-16, 2001.

[6] C. Ayranci, A. Fahim, and M. Munro, "A novel strain sensor for reinforced concrete structures," Strain, vol. 44, no. 2, pp. 191200, 2008.

[7] C. I. Merzbacher, A. D. Kersey, and E. J. Friebele, "Fiber optic sensors in concrete structures: a review," Smart Materials and Structures, vol. 5, no. 2, pp. 196-208, 1996.

[8] A. Kenel, P. Nellen, A. Frank, and P. Marti, "Reinforcing steel strains measured by bragg grating sensors," Journal of Materials in Civil Engineering, vol. 17, no. 4, pp. 423-431, 2005.

[9] U. Meier, "Brückensanierungen mit hochleistungsfaserverbundwerkstoffen," Material und Technik, vol. 4, pp. 125-128, 1987.

[10] U. Meier, "Strengthening of structures using carbon fibre/epoxy composites," Construction and Building Materials, vol. 9, no. 6, pp. 341-351, 1995.

[11] P.-W. Chen and D. D. L. Chung, "Carbon fiber reinforced concrete for smart structures capable of non-destructive flaw detection," Smart Materials and Structures, vol. 2, no. 1, pp. 2230, 1993. 
[12] W. Wang, H. Dai, and S. Wu, "Mechanical behavior and electrical property of CFRC-strengthened RC beams under fatigue and monotonic loading," Materials Science and Engineering A, vol. 479, no. 1-2, pp. 191-196, 2008.

[13] D. D. L. Chung, "Self-monitoring structural materials," Materials Science and Engineering R: Reports, vol. 22, no. 2, pp. 57-78, 1998.

[14] R. Salvado, C. Lopes, L. Szojda et al., "Carbon fiber epoxy composites for both strengthening and health monitoring of structures," Sensors, vol. 15, no. 5, pp. 10753-10770, 2015. 


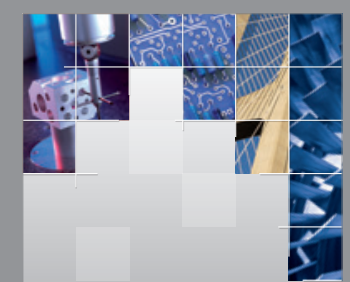

\section{Enfincering}
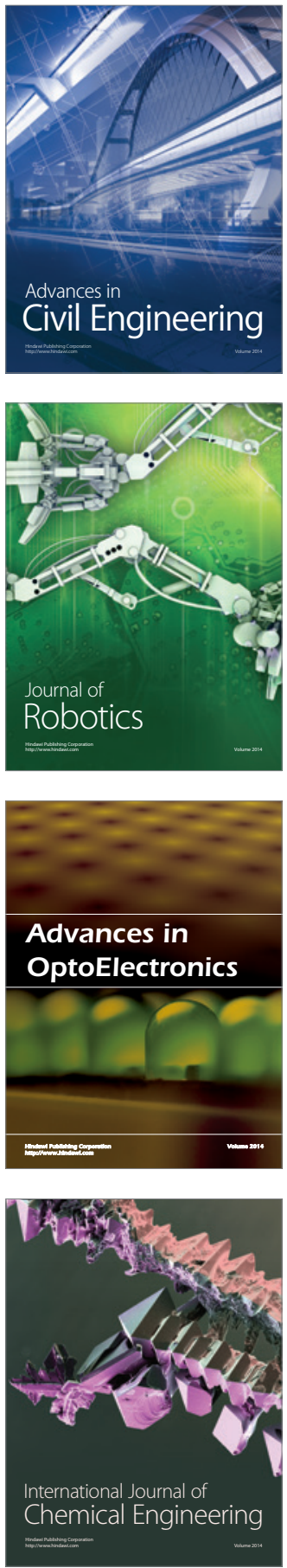

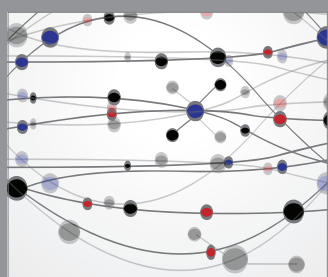

The Scientific World Journal

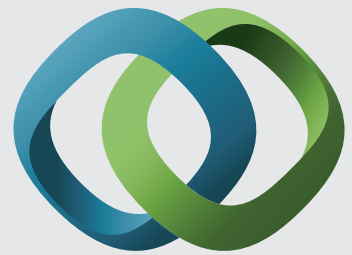

\section{Hindawi}

Submit your manuscripts at

http://www.hindawi.com
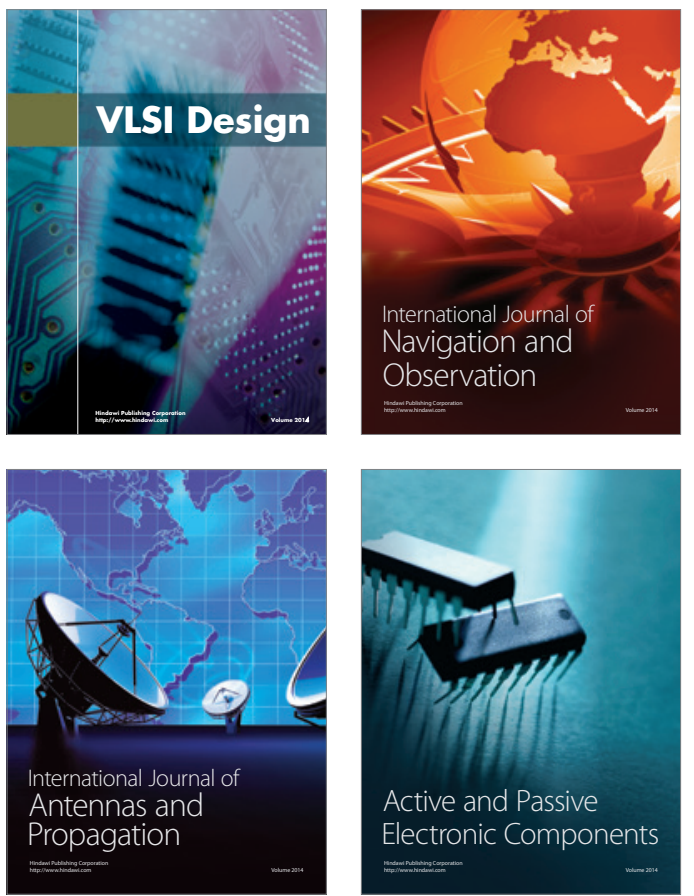
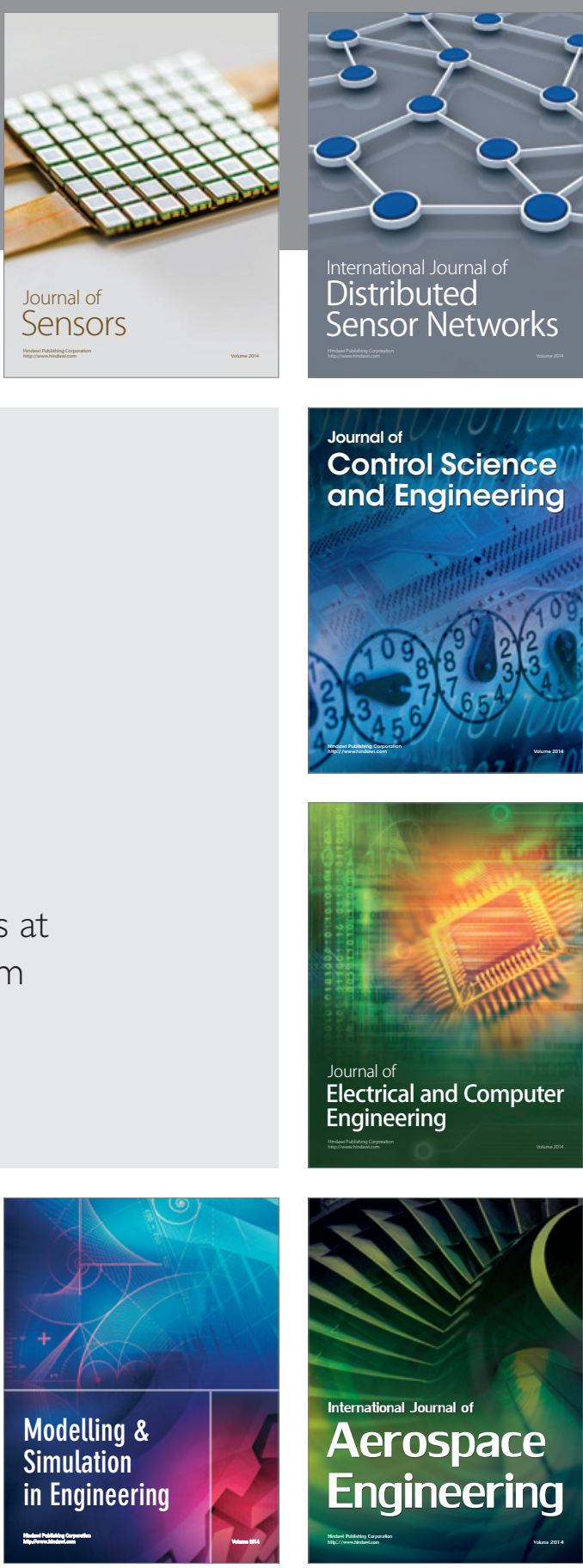

International Journal of

Distributed

Sensor Networks

Journal of

Control Science

and Engineering
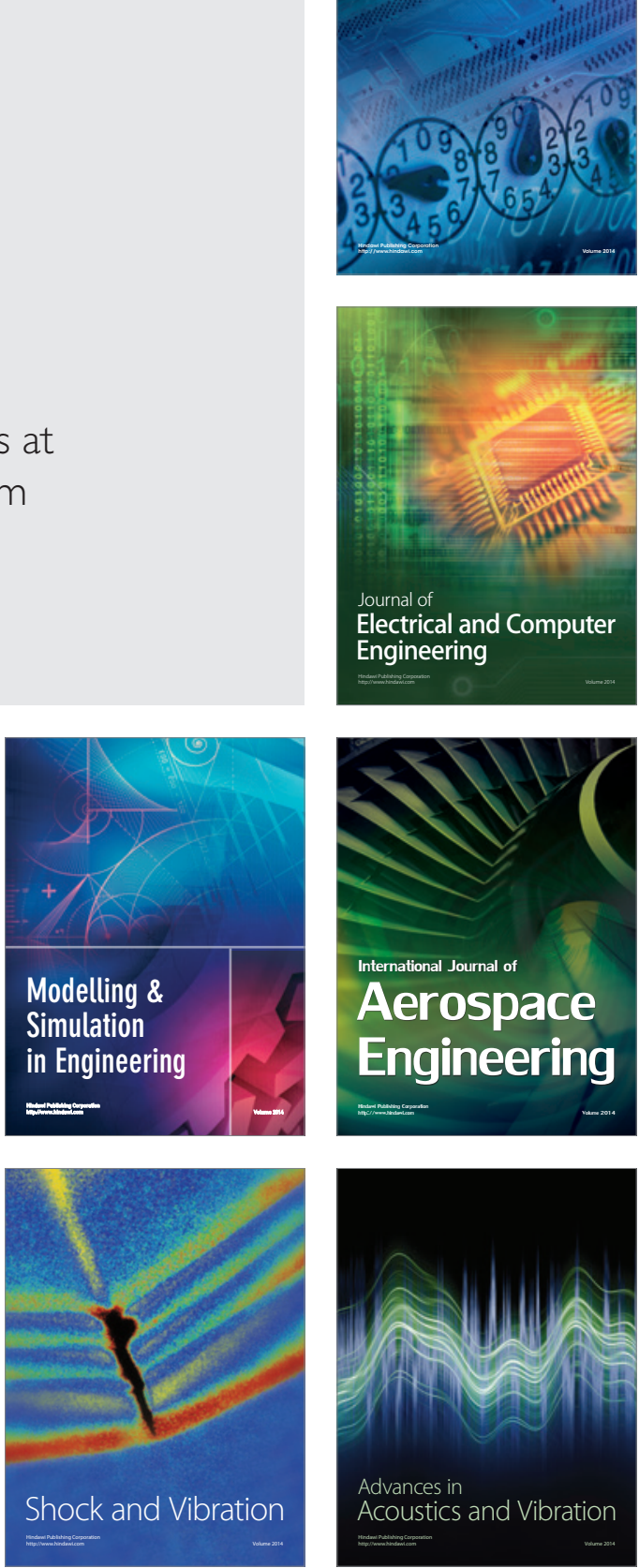